\title{
PENGEMBANGAN BUKU AJAR KALKULUS INTEGRAL BERBASIS MAPLE UNTUK MENINGKATKAN PEMAHAMAN KONSEP MAHASISWA
}

\author{
Yusak I. Bien ${ }^{1 凶}{\text {, Farida } \text { Daniel }^{2} \text {, Prida N. L. Taneo }}^{3}$ \\ ${ }^{1,2,3}$ Prodi Pendidikan Matematika, STKIP Soe.
}

\begin{tabular}{|c|c|}
\hline Info Artikel & Abstract \\
\hline $\begin{array}{l}\text { Sejarah Artikel: } \\
\text { Diterima 15 Mei } 2019 \\
\text { Direvisi } 25 \text { Mei } 2019 \\
\text { Disetujui } 26 \text { Mei } 2019 \\
\text { Keywords: calculus } \\
\text { integral, concepts' } \\
\text { understanding, maple, } \\
\text { materials (book) } \\
\text { Paper type: } \\
\text { Research paper }\end{array}$ & $\begin{array}{l}\text { This study aims to analyze: (1) the validity of maple-based integral calculus textbooks; (2) the } \\
\text { effectiveness of textbooks that have been designed to increase understanding of students mathematical } \\
\text { concepts; (3) the practicality of textbooks that have been designed to increase understanding of } \\
\text { students' mathematical concepts. The method used in this study was research and development ( } R \text { \& } \\
D \text { ) with the design of the development of the Plomp model which consists of five stages in the form of } \\
\text { (1) initial investigation, (2) design, (3) realization / construction, (4) test, evaluation and revision, (5) } \\
\text { implementation. The research subjects were the STKIP Soe mathematics education students in the } \\
\text { even semester 2017/2018 academic year who took integral calculus courses consisting of } 2 \text { (two) } \\
\text { classes namely the experimental class consisting of } 14 \text { people and a control class consisting of } 15 \\
\text { people. Instruments and data collection techniques used in the form of observations, tests and } \\
\text { questionnaires. Data analysis using independent sample t test and normalization gain score. The } \\
\text { result of this study showed that the calculus integral materials (book) maple based was valid, } \\
\text { effective and practical in increasing students' math understanding concept. }\end{array}$ \\
\hline
\end{tabular}

\begin{abstract}
Abstrak
Penelitian ini bertujuan untuk menganalisis: (1) kevalidan buku ajar kalkulus integral berbasis maple; (2) keefektifan buku ajar yang telah dirancang terhadap peningkatan pemahaman konsep matematis mahasiswa; (3) kepraktisan buku ajar yang telah dirancang terhadap peningkatan pemahaman konsep matematis mahasiswa. Metode yang digunakan adalah penelitian dan pengembangan dengan desain pengembangan model Plomp yang terdiri dari lima tahapan berupa (1) investigasi awal, (2) desain, (3) realisasi/konstruksi, (4) tes, evaluasi dan revisi, (5) implementasi. Subjek penelitian adalah mahasiswa pendidikan matematika STKIP Soe semester genap tahun ajaran 2017/2018 yang mengambil mata kuliah kalkulus integral yang terdiri dari 2 (dua) kelas yakni kelas eksperimen terdiri dari 14 orang dan kelas kontrol yang terdiri dari 15 orang. Instrumen dan teknik pengumpulan data yang digunakan berupa observasi, tes dan angket. Analisis data menggunakan uji t sampel independen dan skor gain normalisasi. Hasil penelitian menunjukkan bahwa buku ajar kalkulus integral berbasis maple valid, efektif dan praktis untuk meningkatkan pemahaman konsep mahasiswa.
\end{abstract}

(C) 2019 Universitas Muria Kudus 


\section{PENDAHULUAN}

Matematika adalah salah satu cabang ilmu yang penting dan diajarkan mulai dari tingkat sekolah dasar hingga perguruan tinggi, diharapkan mampu membentuk pribadi seseorang agar menjadi manusia yang berkualitas. Pendidikan merupakan suatu proses pembentukan pola pikir manusia yang memungkinkan untuk tumbuh dan berkembang sesuai dengan kemampuannya. Agar orang-orang terdidik dimasa depan mempunyai kemampuan seperti yang dikemukakan tadi diperlukan sistem pendidikan yang berorientasi pada pemecahan masalah, kemampuan berpikir kritis, kreatif, sistematis dan logis.

Pemahaman konsep setara dengan tahapan pemahaman dan pengetahuan dasar yang menjadi tolak ukur bagi kemampuan berpikir tingkat tinggi matematis siswa seperti kemampuan pemecahan masalah, kemampuan komunikasi matematis, kemampuan penalaran dan representatif dan kemampuan berpikir kritis dan kreatif. Pemahaman konsep merupakan kemampuan yang berkenaan dengan memahami ide-ide matematika yang menyeluruh dan fungsional. Pemahaman konsep lebih penting daripada sekedar menghafal (Fahrudin, Zuliana dan Bintoro, 2018).

Pemahaman konsep adalah kemampuan menjelaskan suatu situasi dengan kata-kata yang berbeda dan dapat menginterpretasikan atau menarik kesimpulan dari tabel, data, grafik dan sebagainya (Susanto, 2013). Indikator pemahaman konsep yang digunakan dalam penelitian ini adalah (1) menyatakan ulang sebuah konsep, (2) mengklasifikasi objek-objek menurut sifat-sifat tertentu, (3) memberi contoh dan non contoh dari konsep,(4) menyajikan konsep dalam berbagai bentuk representasi matematis, mengembangkan syarat perlu atau syarat cukup suatu konsep, (6) menggunakan, memanfaatkan, dan memilih prosedur atau operasi tertentu, dan (7) mengaplikasikan konsep atau algoritma pemecahan masalahnya (Wardhani, 2010).

Pemahaman konsep merupakan suatu aspek yang sangat penting dalam pembelajaran, karena dengan memahami konsep pembelajar dapat mengembangkan kemampuannya dalam setiap materi pelajaran. Akan tetapi, berdasarkan hasil observasi yang dilakukan pada mahasiswa program studi pendidikan matematika STKIP Soe, tampak bahwa dalam proses pembelajaran dijumpai banyak mahasiswa mengalami kesulitan dalam memahami konsep matematika.

Hasil analisis terhadap kesulitan mahasiswa dalam mempelajari kalkulus lanjut, terindikasi bahwa mahasiswa kurang menguasai konsep materi kalkulus differensial dan kalkulus integral. Selain itu hasil wawancara terhadap mahasiswa diperoleh informasi bahwa salah satu penyebab kurangnya penguasaan konsep dalam matakuliah kalkulus adalah kurangnya bahan bacaan dalam mempersiapkan diri untuk mengikuti perkuliahan. Sementara belum ada buku sebagai bahan ajar yang praktis dari dosen sebagai pegangan mahasiswa dalam perkuliahan. Bahan ajar yang dipakai hanya buku-buku yang ada di perpustakaan saja, itupun jumlahnya terbatas. Keterbatasan bahan bacaan mengakibatkan penguasaan konsep kalkulus integral rendah; agar mahasiswa mengalami kemudahan dalam memahami berbagai konsep dalam perkuliahan maka perlu disusun dan dikembangkan buku ajar yang dapat mengarahkan dan merangsang proses berpikir mahasiswa dalam memaksimalkan pemahaman konsep matematis mahasiswa.

Buku merupakan salah satu bahan ajar cetak yang disusun sedemikian rupa sehingga siswa dapat belajar secara individual. Menurut Sabri (2007), buku adalah suatu unit lengkap yang terdiri dari rangkaian kegiatan belajar disusun untuk membantu siswa dalam mencapai tujuan yang telah dirumuskan. Buku merupakan suatu paket kurikulum yang disediakan untuk dapat digunakan siswa agar belajar sendiri, sehingga tanpa kehadiran guru siswa dapat belajar secara mandiri.

Buku ajar merupakan sebuah karya tulis yang berbentuk buku dalam bidang tertentu, yang merupakan buku standar yang digunakan guru dan siswa dalam proses belajar mengajar untuk maksud-maksud dan tujuan instruksional yang dilengkapi dengan sarana-sarana pengajaran yang serasi dan mudah dipahami oleh pemakainya di sekolah-sekolah dan perguruan tinggi sehingga dapat menunjang program pengajaran (Mudlofir, 2011). Hal ini menunjukkan bahwa buku ajar merupakan bagian yang penting dalam pembelajaran karena dapat digunakan sebagai sumber belajar baik bagi dosen maupun mahasiswa. Oleh karena itu, perlu mendesain buku ajar sebagai salah satu sumber belajar bagi mahasiswa.

Pemilihan dan penggunaan buku ajar yang tepat dalam proses perkuliahan merupakan faktor yang sangat penting untuk pemahaman konsep mahasiswa, sebagaimana hasil penelitian Mukhtar (2013) bahwa pengembangan bahan ajar berbasis masalah dapat memfasilitasi pencapaian kemampuan penalaran dan pemahaman konsep matematika siswa. Penggunaan modul sebagai bahan ajar membantu dosen dalam menyampaikan materi perkuliahan sehingga pencapaian kompetensi disetiap materi oleh mahasiswa dapat dilakukan dengan baik (Fitria, Arnawa dan Lufri, 2014). Pengembangan bahan ajar yang didesain berdampak pada 
pemahaman konsep matematika (Nuranisa, Nu'man dan Arfinanti 2015).

Selain itu, untuk mengantisipasi adanya perkembangan ilmu pengetahuan dan teknologi saat ini, maka persiapan perangkat pembelajaran berbasis teknologi dan informatika sangat dibutuhkan. Oleh karena itu, berbagai media pembelajaran dapat digunakan untuk membantu mahasiswa dalam penguasaan konsep. Salah satu media pembelajaran berbasis teknologi adalah maple. Pengembangan sumber pengajaran kalkulus dengan menggunakan program maple sangat efektif, pemahaman dan gambaran mahasiswa meningkat secara signifikan serta mahasiswa dapat menyelesaikan soal dengan tepat (Andriani, 2012 serta Qodaryah dan Ismai, 2012). Selain itu Purnomo, Fathurohman dan Budiharto (2014) menerapkan pembelajaran berbasis maple sebagai alternatif untuk meningkatkan keterampilan berproses, motivasi dan kemampuan pemecahan masalah. Purnomo dan Rohman (2015) juga menerapkan pembelajaran berbasis maple dan diperoleh bahwa kemampuan pemecahan masalah siswa setelah perlakuan lebih baik dari sebelum perlakuan.

Buku ajar yang dikembangkan pada penelitian ini memuat konsep-konsep kalkulus integral beserta contoh masalah dan penyelesaiannya dengan software Maple. Maple sebagai alat pembelajaran. Maple merupakan suatu software yang kemampuannya tidak hanya sebagai alat hitung seperti halnya kalkulator tangan biasa, namun lebih jauh dari itu, dapat digunakan sebagai alat pembelajaran matematika khususnya kalkulus (Qodariyah dan Ismai, 2012).

Penelitian ini bertujuan untuk menganalisis: (1) kevalidan buku ajar kalkulus integral berbasis maple; (2) keefektifan buku ajar yang telah dirancang terhadap peningkatan pemahaman konsep matematis mahasiswa; (3) kepraktisan buku ajar yang telah dirancang terhadap peningkatan pemahaman konsep matematis mahasiswa.

\section{METODE PENELITIAN}

Jenis penelitian yang digunakan adalah penelitian dan pengembangan (research and development). Desain penelitian dan pengembangan mengikuti model Plomp (Rochmad, 2012) yang terdiri dari lima tahapan yaitu (1) tahap investigasi awal; (2) tahap desain; (3) tahap realisasi/konstruksi; (4) tahap tes, evaluasi, dan revisi; dan (5) tahap implementasi.

Penelitian ini dilakukan di STKIP Soe pada semester genap tahun ajaran 2017/2018. Subjek pada penelitian ini adalah mahasiswa program studi pendidikan matematika STKIP Soe yang mengambil mata kuliah kalkulus integral terdiri dari kelas eksperimen sebanyak 14 orang dan kelas kontrol sebanyak 15 orang. Kelas penelitian ditentukan menggunakan teknik simple random sampling.

Instrumen dan teknik pengumpulan data yang digunakan berupa: (1) observasi digunakan untuk mengetahui proses belajar matakuliah kalkulus integral; (2) tes digunakan untuk mengumpulkan data mengenai kemampuan pemahaman konsep matematis mahasiswa; (3) angket digunakan untuk mengukur kepraktisan buku ajar yang dikembangkan berupa respon mahasiswa dan teman sejawat.

Buku ajar yang dikembangkan diuji validitasnya terlebih dahulu oleh tim ahli, setelah dinyatakan valid diuji keefektifan dan kepraktisannya. Pengujian validitas buku ajar menggunakan rumus berikut:

$$
\begin{aligned}
& P v=\frac{\text { jumlah skor rata }- \text { rata }}{\text { jumlah aspek penilaian }} \times 100 \%, \\
& P v: \text { persentasi validitas }
\end{aligned}
$$

Kualitas buku ajar yang dikembangkan dikatakan siap digunakan jika persentasi dari hasil validasi oleh validator berada pada kategori interval minimal cukup valid.

Tabel 1. Kriteria Kevalidan Buku Ajar

\begin{tabular}{ll}
\hline Interval & Kategori \\
\hline $85 \%<P v \leq 100 \%$ & Sangat valid \\
$70 \%<P v \leq 85 \%$ & Cukup Valid \\
$50 \%<P v \leq 70 \%$ & Kurang valid \\
$0 \%<P v \leq 50 \%$ & Tidak valid \\
\hline & Akbar (2013)
\end{tabular}

Produk buku ajar yang dikembangkan dalam penelitian ini diuji validitasnya oleh tiga validator dengan mengambil rata-ratanya.

Uji keefektifan buku ajar dalam meningkatkan pemahaman konsep dilakukan melalui penelitian quasi eksperimen (Creswell, 2014). Desain pada uji keefektifan melibatkan dua kelas sampel, yaitu kelas eksperimen (diajarkan menggunakan buku ajar berbasis maple) dan kelas kontrol (tidak diajarkan menggunakan buku tersebut). Pre-test diberikan kepada kelas eksperimen dan kelas kontrol untuk mengetahui kemampuan awal mahasiswa. Kelas eksperimen dikenai perlakuan/treatment yakni pembelajaran dilaksanakan dengan menerapkan buku ajar yang didesain. Pada akhir pembelajaran, dilaksanakan post-test bagi mahasiswa pada kelas eksperimen dan kelas kontrol untuk mengetahui kemampuan akhir mahasiswa dalam memahami konsep kalkulus integral. Soal pre-test dan post-test sebelum digunakan terlebih dahulu diujicobakan untuk mengetahui tingkat validitas dan reliabilitasnya.

Analisis uji keefektifan buku ajar dengan menggunakan rumus berikut: 
Rumus uji $t_{\text {dua }}$ pihak dengan taraf signifikansi $(\alpha=0,05)$, adalah:

$$
t_{\text {hitung }}=\frac{\overline{x_{1}}-\overline{x_{2}}}{\sqrt{\left\{\frac{s_{1}{ }^{2}}{n_{1}}+\frac{s_{2}{ }^{2}}{n_{2}}\right\}}}
$$

(Sudjana, 2005)

Uji gain normalisasi $(g)$ digunakan untuk mengetahui besar peningkatan pemahaman konsep mahasiswa sebelum perlakuan dan setelah mendapat perlakuan pada kelas eksperimen yang dihitung menggunakan rumus gain normalisasi sebagai berikut:

$$
g=\frac{s_{\text {post }}-s_{\text {pre }}}{s_{\text {maks }}-s_{\text {pre }}} \text { (Hake,1999) }
$$

Tabel 2. Kriteria Peningkatan Pemahaman Konsep

\begin{tabular}{cc}
\hline Skor Gain & Kategori \\
\hline$g<0,3$ & Rendah \\
$0,3 \leq g<0,7$ & Sedang \\
$g \geq 0,7$ & Tinggi \\
\hline
\end{tabular}

Buku ajar yang didesain dikatakan efektif meningkatkan pemahaman konsep jika berdasarkan uji t sampel independent, terdapat perbedaan pemahaman konsep pada kedua kelas penelitian dan berdasarkan thitung diperoleh kelas eksperimen lebih baik dari kelas kontrol, serta berdasarkan uji gain normalisasi terdapat peningkatan pemahaman konsep mahasiswa minimal berada pada kategori sedang.

Uji kepraktisan buku ajar yang dikembangkan ditentukan melalui respon mahasiswa dan teman sejawat (dosen) terhadap buku ajar yang dikembangkan dan proses pembelajaran (perkuliahan) dengan menggunakan skala Likert. Pengujian kepraktisan menggunakan rumus berikut:

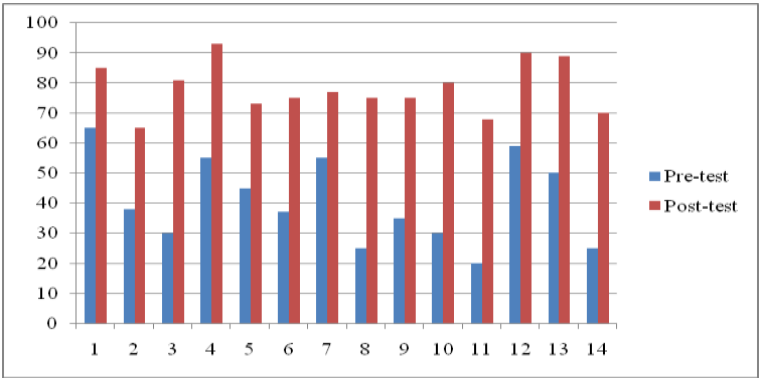

Gambar 1. Hasil Tes Kelas Eksperimen

$$
x=\frac{\text { jumlah skor }}{\text { jumlah aspek penilaian }}
$$

Jika hasil analisis angket mencapai kriteria setuju dan sangat setuju maka produk yang dikembangkan praktis digunakan sebagai sumber pembelajaran.

Tabel 3. Hasil Angket Respon terhadap Buku Ajar

\begin{tabular}{ccc}
\hline No & Angka Mutu & Kategori \\
\hline 1 & $4<x \leq 5$ & Sangat setuju \\
2 & $3<x \leq 4$ & Setuju \\
3 & $2<x \leq 3$ & Ragu-ragu \\
4 & $1<x \leq 2$ & Tidak setuju \\
5 & $0<x \leq 1$ & Sangat tidak setuju \\
\hline
\end{tabular}

\section{HASIL DAN PEMBAHASAN}

Sebelum menguji keefektifan dan kepraktisan buku ajar yang dikembangkan terlebih dahulu menguji kevalidannya. Hasil validasi buku ajar oleh tiga validator seperti pada Tabel 4.

Tabel 4. Hasil Validasi Buku Ajar

\begin{tabular}{ccc}
\hline No & Validator & Penilaian (\%) \\
\hline 1 & Validator 1 & 89,23 \\
2 & Validator 2 & 92,31 \\
3 & Validator 3 & 90,77 \\
& Rata-rata & 90,77 \\
\hline
\end{tabular}

Hasil validasi pada Tabel 4 menunjukkan bahwa buku ajar yang dikembangkan 'sangat valid' karena berada pada rentangan $(85 \%<P v \leq 100 \%)$ sehingga buku tersebut layak untuk digunakan. Selain itu, uji coba soal pre-test dan post-test diperoleh soal valid dan reliabel sehingga soal-soal tersebut layak digunakan untuk mengukur kemampuan pemahaman konsep mahasiswa.

Hasil pre-test dan post-test kemampuan pemahaman konsep mahasiswa pada kelas eksperimen dan kelas kontrol disajikan pada Gambar 1 dan Gambar 2. Secara ringkas, hasil tes kemampuan pemahaman konsep mahasiswa disajikan pada Tabel 5.

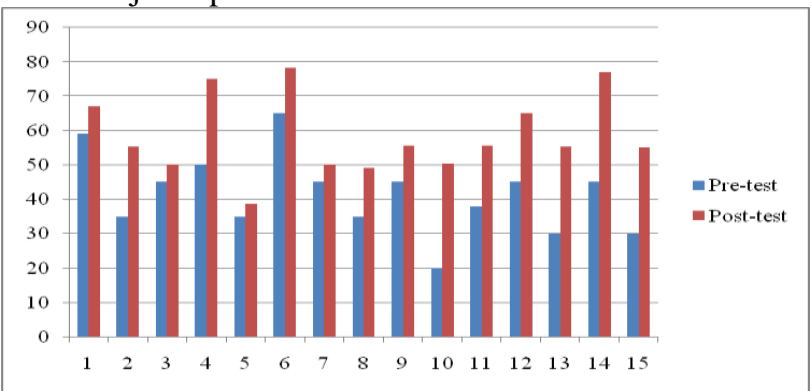

Gambar 2. Hasil Tes Kelas Kontrol

Tabel 5. Hasil Tes Kemampuan Pemahaman Konsep Mahasiswa

\begin{tabular}{lllll}
\hline Statistik & $\begin{array}{l}\text { Kelas Eksperimen }(\boldsymbol{n}=\mathbf{1 4}) \\
\text { Pre-test }\end{array}$ & Post-test & \multicolumn{2}{l}{$\begin{array}{l}\text { Kelas Kontrol }(\boldsymbol{n}=\mathbf{1 5}) \\
\text { Pre- } \\
\text { test }\end{array}$} \\
\hline Nilai Tertinggi & 65 & 90 & 65 & 78 \\
Nilai Terendah & 20 & 65 & 20 & 39 \\
Rata-rata & 40,64 & 78,29 & 41,47 & 58 \\
Simpangan baku & 14,26 & 8,49 & $11,5211,54$ \\
\hline
\end{tabular}


Tabel 5 menunjukkan bahwa kelas eksperimen dan kelas kontrol mengalami peningkatan kemampuan pemahaman konsep dengan hasil perolehan skor pre-test lebih rendah dari skor post-test. Nilai rata-rata post-test pada kelas eksperimen lebih besar dari rata-rata post-test kelas kontrol. Hal ini menunjukkan bahwa kemampuan pemahaman konsep mahasiswa kelas eksperimen lebih baik dari kelas kontrol. Simpangan baku data post-test pada kelas eksperimen lebih kecil dari simpangan baku kelas kontrol. Hal ini menunjukkan bahwa kemampuan pemahaman konsep setiap mahasiswa pada kelas eksperimen cenderung lebih homogen dibandingkan dengan kelas kontrol.

Analisis lanjutan keefektifan buku ajar kalkulus integral berbasis maple terhadap kemampuan pemahaman konsep mahasiswa dilakukan menggunakan uji $t$ sampel independen yang sebelumnya dilakukan uji normalitas dan hasilnya menunjukkan bahwa sampel berasal dari populasi yang berdistribusi normal dan uji homogenitas menunjukkan bahwa kedua sampel penelitian berasal dari populasi yang homogen.

Berdasarkan hasil uji $t$ sampel independen dengan $\alpha=0,05$ diperoleh $\mathrm{t}_{\text {hitung }}=5,254>\mathrm{t}_{\text {tabel }}=$ 2,045 yang berarti bahwa kemampuan pemahaman konsep mahasiswa dalam mempelajari kalkulus integral yang diajarkan menggunakan buku ajar berbasis maple lebih baik dari kelas yang tidak diajarkan menggunakan buku ajar tersebut. Hasil ini menunjukkan bahwa buku ajar yang dikembangkan dapat membantu mahasiswa untuk memahami konsep pembelajaran kalkulus integral. Hal ini sebagaimana hasil penelitian Nuranisa, Nu'man dan Arfinanti (2015) bahwa pengembangan bahan ajar yang didesain berdampak pada pemahaman konsep matematika. Bahan ajar yang dikembangkan menggunakan maple memiliki efek potensial terhadap hasil belajar (Paradesa, Zulkardi dan Darmawijoyo, 2010).

Setelah mengetahui hasil pembelajaran pada kelas eksperimen lebih baik selanjutnya diuji besar peningkatan kemampuan pemahaman konsep dengan menggunakan uji gain normalisasi dan diperoleh hasil skor gain $=0,63$ yang berarti kemampuan pemahaman konsep mahasiswa pada kelas eksperimen mengalami peningkatan dengan besar peningkatan berada pada kategori sedang. Peningkatan pemahaman konsep mahasiswa dalam mempelajari matakuliah kalkulus integral karena buku yang yang dikembangkan berbasis maple. Afgani (2016) menyimpulkan bahwa pemahaman konsep dapat ditanamkan kepada siswa dengan menggunakan animasi atau Maplet Builder yang terdapat dalam menu Assistants dimana Dosen dapat membuat suatu Maplet interaktif yang dapat digunakan dalam pembelajaran kalkulus .

Uji kepraktisan buku ajar yang dikembangkan dilakukan melalui angket respon mahasiswa sebanyak 14 orang dan respon dosen sebanyak 2 orang. Hasil analisis angket diringkas pada Tabel 6.

Tabel 6. Hasil Angket Respon terhadap Buku

\begin{tabular}{llll}
\multicolumn{4}{c}{ Ajar } \\
\hline No & Respon & Penilaian (\%) & Angka Mutu \\
\hline 1 & Mahasiswa & 93,21 & 4,66 \\
2 & Dosen & 91,33 & 4,57 \\
& Rata-rata & 92,27 & 4,62
\end{tabular}

Kepraktisan buku ajar yang dikembangkan diketahui dengan memberikan angket kepada mahasiswa dan dosen. Berdasarkan hasil analisis pada Tabel 6, diperoleh rata-rata persentase respon mahasiswa dan dosen sebesar $92,27 \%$ dengan angka mutu adalah 4,62 berarti respon mahasiswa dan dosen berada pada kategori 'sangat setuju' yang menunjukkan bahwa buku ajar kalkulus integral berbasis maple praktis untuk digunakan dalam pembelajaran (perkuliahan) pada mahasiswa pendidikan matematika STKIP Soe. Hal ini disebabkan karena pembelajaran kalkulus integral dengan menggunakan aplikasi maple membantu mahasiswa termotivasi dalam menyelesaikan soalsoal yang diperoleh.

Keefektifan dan kepraktisan buku ajar kalkulus integral berbasis maple yang dikembangkan didukung dengan hasil observasi saat proses pembelajaran diketahui bahwa mahasiswa termotivasi dalam pembelajaran karena menggunakan buku ajar yang didesain oleh dosennya sendiri dan buku yang digunakan dilengkapi dengan aplikasi maple yang dapat digunakan dalam menggambar dan memvisualisasikan grafik serta menyelesaikan soal yang diperoleh.

Aplikasi maple yang digunakan juga memotivasi mahasiswa agar mencoba menyelesaikan soal secara manual berulang-ulang sampai memperoleh jawaban yang tepat untuk menyesuaikan dengan hasil yang diperoleh dengan menggunakan aplikasi tersebut. Hal ini sesuai hasil penelitian Suhandri (2016) bahwa peningkatan motivasi belajar mahasiswa dalam perkuliahan kalkulus melalui pemanfaatan program aplikasi maple lebih baik daripada mahasiswa yang mendapatkan pembelajaran konvensional. 


\section{SIMPULAN}

Berdasarkan hasil dan pembahasan dapat disimpulkan bahwa buku ajar kalkulus integral berbasis maple valid dan layak digunakan dalam pembelajaran serta efektif dan praktis untuk meningkatkan pemahaman konsep mahasiswa.

1. Valid, berdasarkan hasil validasi ketiga validator, isi materi pada buku ajar yang dikembangkan sesuai dengan capaian pembelajaran mata kuliah kalkulus 2 (kalkulus integral) dan bahasa yang digunakan sesuai dengan ejaan yang disempurnakan (EYD).

2. Efektif, pemahaman konsep mahasiswa setelah menggunakan buku ajar yang dikembangkan pada kelas eksperimen lebih baik dari kelas kontrol yang ditunjukkan melalui nilai rata-rata post-test pada kelas eksperimen adalah 78,29 lebih besar dari rata-rata post-test kelas kontrol adalah 58. Peningkatan pemahaman konsep pada kelas eskperimen berada pada kategori sedang.

3. Praktis, mahasiswa pendidikan matematika telah menggunakan buku ajar yang dikembangkan, respon mahasiswa dan dosen sangat setuju dengan buku ajar yang telah dikembangkan yang menunjukkan bahwa buku ajar kalkulus integral berbasis maple praktis untuk digunakan dalam pembelajaran (perkuliahan).

\section{UCAPAN TERIMAKASIH}

Ucapan terimakasih diberikan kepada Direktorat Riset dan Pengabdian (DRP) Dirjen DIKTI yang memberikan bantuan dana kepada tim peneliti dalam memperlancar kegiatan penelitian ini melalui hibah desentralisasi Penelitian Dosen Pemula (PDP).

\section{DAFTAR PUSTAKA}

Afgani, M.W. 2016. Pemecahan Masalah dan Menanam Pemahaman Konsep Matematika melalui Software Maple. Jurnal Pendidikan Matematika JPM RAFA, 2 (1): 85-103.

Akbar, S. 2013. Instrumen Perangkat Pembelajaran. Bandung: Remaja Rosdakarya Offset.

Andriani, S. 2012. Pengembangan Bahan Ajar Praktikum Kalkulus melalui Program Maple untuk Meningkatkan Penalaran dan Representasi Mahasiswa. Atikan, 2 (2): 295-312.

Creswell, J.W. 2014. Research Design Pendekatan Kualitatif, Kuantitatif, dan
Mixed. Terjemahan Achmad Fawaid. Yogyakarta: Pustaka Pelajar.

Fahrudin, A.G., Zuliana, E., Bintoro, H.S. 2018. Peningkatan Pemahaman Konsep Matematika melalui Realistic Mathematic Education Berbantu Alat Peraga. Anargya: Jurnal Pendidikan Matematika, 1 (1): 14-20.

Fitria, M., Arnawa, M., Lufri. 2014. Pengembangan Modul Aljabar Linear Elementer bernuansa Konstruktivisme berbantuan ICT. Jurnal Eksakta, 1: 3442.

Hake, R, R. 1999.Analyzing Change/Gain Scores.AREA-D American Education Research Association's Devision.D, Measurement and Reasearch Methodology.

Mudlofir, Ali. 2011. Aplikasi Pengembangan Kurikulum Tingkat Satuan Pendidikan dan Bahan Ajar. Jakarta: Raja Grafindo Persada.

Mukhtar. 2013. Pengembangan Bahan Ajar Matematika berbasis Masalah untuk Memfasilitasi Pencapaian Kemampuan Penalaran dan Pemahaman Konsep Siswa. Prosiding Semirata FMIPA Universitas Lampung FMIPA Unila, 353- 360.

Nuranisa, R. A., Nu'man, M., Arfinanti, N. 2015. Pengembangan Bahan Ajar dengan Model Group Invesigation dalam Memfasilitasi Pemahaman Konsep Matematika. Seminar Nasional dan Pendidikan Matematika UNY, ISBN. 978-602-73403-0-5, 697-704.

Paradesa, R., Zulkardi dan Darmawijoyo. 2010. Bahan Ajar Kalkulus 2 menggunakan Macromedia Flash dan Maple di STKIP Lubuklinggau. Jurnal Pendidikan Matematika, 4 (1): 95109.

Purnomo, E. A., Fathurohman, A., Budiharto. 2014. Keefektifan Model Pembelajaran Ideal Problem Solving berbasis Maple Matakuliah Kalkulus II. JKPM, 1 (2): 7-11.

Purnomo, E. A., Rohman, A. 2015. Pengembangan Perangkat Pembelajaran Project Based Learning (PBL) berbasis Maple Matakuliah Kalkulus Lanjut II. The 2nd University Research Coloquium. ISSN 24079189, 164-172. 
Rochmad. 2012. Desain Model Pemngembangan Perangkat Pembelajaran Matematika. Jurnal Kreano, 3 (1): 59-72.

Sabri, H. Ahmad. 2007. Strategi Belajar Mengajar dan Micro Teaching. Ciputat :Quantum Teaching.

Sudjana. 2005. Metoda Statistika. Bandung: Tarsito

Suhandri. 2016. Implementasi Program Aplikasi Maple untuk Meningkatkan Prestasi dan Motivasi Belajar Mahasiswa pada Perkuliahan Kalkulus Integral. Suska Journal of Mathematics Education, 2 (1): 57-66.

Susanto, A. 2013. Teori Belajar dan Pembelajaran di Sekolah Dasar. Jakarta: Kencana Prenamedia Group.

Qodaryah, E., Ismai, A. D. 2012. Pembelajaran Kalkulus dengan Bantuan Maple. Jurnal Humanity, 8 (1): 144-154.

Wardhani, S. 2010. Teknik Pengembangan Instrumen Penilaian Hasil Belajar Matematika di SMP/MTs. Yogyakarta: Tenaga Kependidikan (P4TK) Matematika. 